

\title{
AIDS and intravenous drug use: the real heterosexual epidemic
}

"Prevention of the spread of the human immunodeficiency virus (HIV) must take priority over any perceived risk of increasing drug misuse," recommended the Scottish committee on HIV infection and intravenous drug use set up because so many intravenous drug users from Edinburgh were infected with HIV. ${ }^{2}$ Similar conclusions have been reached in the United States, where the acquired immune deficiency syndrome (AIDS) was reported in drug users in 1981. What is most alarming in the United States is the heterosexual spread of HIV from drug users to the rest of the population.

About $17 \%$ of all American cases of AIDS, $30 \%$ of those in New York City, and half of those in New Jersey have been in intravenous drug users. Cities elsewhere have been complacent about their lower case rates, but at the second national conference on AIDS it was reported that $5-20 \%$ of American intravenous drug users were infected with HIV. Furthermore, $90 \%$ of infected prostitutes reported in Florida, Seattle, New York, and San Francisco have been intravenous drug users: thus drug use is the main route of HIV into prostitutes. ${ }^{23}$ And in Belle Glade, Florida, which has a local epidemic of almost African proportions, half the cases are among drug users and their sexual partners. ${ }^{4}$

Heterosexual transmission of AIDS in the United States is mostly from drug users. Three quarters of those who have contracted the disease heterosexually have done so from index cases who were intravenous drug users (Centers for Disease Control, unpublished observations). Bisexual behaviour is much less important. In San Francisco, where the epidemic among male homosexuals ( 2500 cases of AIDS and 25000 with antibodies to HIV) dwarfs the epidemic among intravenous drug users (40 cases and 1500 with antibodies), three cases have been attributed to heterosexual transmission from intravenous drug users and three to bisexuality. ${ }^{5}$ Thus the rapid spread of HIV in drug users appears to be the main source for any future heterosexual epidemic. Drug use is also the source of most neonatal AIDS, with $70 \%$ of cases occurring in children of intravenous drug users or their sexual partners (Centers for Disease Control, unpublished observations).

In Europe $14 \%$ of cases of AIDS are in intravenous drug users, and the proportion is rising rapidly. ${ }^{6}$ As many as 30 $70 \%$ of intravenous drug users in southern Spain, southern France, and much of Italy have been reported to be infected with HIV, and serial data from Milan suggest that, as in Edinburgh, infection rates can explode among intravenous drug users, rising from $5 \%$ to $50 \%$ in two or three years $(G$ Rezza, unpublished observations). The Italian data are particularly alarming because needles and syringes are freely available in Italy. As in the United States, infection in drug users leads to infection in their children and heterosexual partners. In Edinburgh, where about 500 women have antibodies to HIV, 22 infants with antibodies were born to addicted mothers in 1986 (not all of those will continue to have antibodies) (J Mok, unpublished observations). At least 10 partners with antibodies have also been identified ( $R$ P Brettle and J R Robertson, unpublished observations).

Among serum samples from British drug users tested for hepatitis $B$ the number with antibodies has risen from $1 \cdot 7 \%$ in 1984 to $10 \%$ in 1986 . There is a wide local variation, with low rates in south London, Manchester, Liverpool, and Tyneside. ${ }^{17}$ The variation probably reflects the date when the virus became established; in Italy the rate is highest in Milan (62\%), where the virus appeared in 1979.

Which is the population at risk? In the Edinburgh Drug Addiction Study, where more than half the cohort have antibodies to HIV, users average 24 years of age and began using drugs in 1980 or later. ${ }^{8}$ They are part of a nationwide cohort who began using drugs in the early 1980s. (American drug users with antibodies to HIV are 10 years older and mostly began in the 1960 s and 1970 s.) $)^{910}$ Compared with older drug users the new users are younger, more likely to be women, and more likely to live in areas of high unemployment throughout the country rather than to be concentrated in London. ${ }^{112}$ There are about 50000 regular (daily) opiate users in Britain, and about the same number of occasional users. ${ }^{13}$ Perhaps a third smoke rather than inject heroin, but the stability of this preference is not known; thus all must be considered to be at risk for AIDS. These opiate users and their sexual partners must be the primary target for measures to reduce the spread of the virus among heterosexuals. Three approaches have been suggested: providing sterile equipment; targeting health education; and identifying and diverting infected users into treatment.

The recommendation to make clean needles available was endorsed first by the Scottish committee and then by the DHSS. It follows the Amsterdam system, in which addicts exchange used needles for new ones in the city's methadone 
outreach clinics. ${ }^{14}$ Pilot exchange schemes have now been set up in Liverpool, Peterborough, and elsewhere. What effect the exchange has had on HIV infection in Amsterdam is not known, but the system is now used by $30-50 \%$ of opiate injectors and does not appear to have increased the extent of injecting among addicts or the number of needle accidents $(R$ Coutinho, unpublished observations. The organisers point out, however, that the needle exchange is part of an overall "harm reduction" approach to addiction that seeks to minimise the risk to users who continue to inject. There is a consensus among medical and political authorities about this approach, and cooperation was negotiated with the police. At present these conditions do not generally prevail in Britain (Liverpool appears to be a notable exception). Proponents of needle exchanges may want to consider other approaches, including systems based on drug dependency units. Any needle exchange programme should be evaluated. The Italian experience suggests that needle availability alone will not control the epidemic.

Health education targeted at drug users currently consists of posters and leaflets in drug dependency units and voluntary agencies helping drug users. It may not reach the younger more inexperienced users who mav be most at risk. There is a need to make young drug users aware of what AIDS is like. Neither newspapers nor house to house distributions of leaflets are likely to reach this population, but television and radio probably will.

Finally, drug users could be tested to find those who are infected with HIV, and they could then be diverted into long term treatment, with the aim of minimising their use of needles and hence the likelihood of spread. A decision to test means providing long term medical and social care, as well as short term counselling, and runs into widespread fears about confidentiality and the management of infected drug users. The voluntary sector in particular is not convinced of the value of testing, but this approach will pay off where few users are infected and the potential for spread is large-as in Britain. American and Scottish experience suggests that most drug users will cooperate with voluntary testing if they are sure it is confidential, and where there is reluctance to provide needles a screening approach is another way of getting access to drug users.

There is no magic bullet for controlling the spread of HIV in drug users, and approaches must be tailored to local conditions. The Scottish report is right to recommend that local authorities should take charge of this second AIDS epidemic now. Developing consensus on giving out needles or using the antibody test will not be easy, but with the alarming potential for heterosexual transmission we should adopt Napoleon's motto: On s'engage et puis on voit.

Visiting Senior Research Fellow,

Academic Department of Genitourinary Medicine,

Middlesex Hospital Medical School,

London WIN 8AA

and

Adjunct Associate Professor,

Department of Epidemiology and International Health, University of California,

San Francisco 1 Scottish Home and Health Department. HIV Infection in Scotland. Edinburgh: SHHD, 1986. LAV) infection among intravenous drug users. Br Med f 1986;292:527-9.

3 Centers for Disease Control. Heterosexual transmission of human T-lymphotropic virus type IIV lymphadenopathy-associated virus. MMWR 1985;34:561-3.

4 Centers for Disease Control. Acquired Immunodeficiency Syndrome in Western Palm Beach County, Florida. MMWR 1986;35:609-12.

5 Chaisson R, Moss AR, Onishis R, Osmond MA, Carlson J. Human immunodeficiency virus infection in heterosexual drug users in San Francisco. Am $\mathcal{f}$ Publ Health (in press).
6 World Health Organisation Collaborating Center on AIDS. AIDS surveillance in Europe: situation by October 31 1986. Geneva: WHO, 1986.

7 Jesson WJ, Thorp RW, Mortimer PP, Oates JK. Prevalence of anti-HTLV-III in UK risk groups 1984/85. Lancet 1986;i:155.

8 Robertson JR. Drug users in contact with general practice. Br Med f 1985;290:34-5.

Webb G, Wells B, Morgan JR, McManus T. Epidemic of AIDS related virus infection among intravenous drug users. Br Med $\mathcal{F}$ 1986;292:1202.

10 DesJarlais DC, Friedman S, Hopkins W. Risk reduction for the acquired immunodeficiency syndrome among drug users. Ann Intern Med 1985;103:755-9.

11 The Drug Indicators Project. The drug situation in Greater London. London: Birkbeck College, 1986.

12 Pearson G, Gilman M, McIver S. Young people and heroin. London: Health Education Council, 1985. (HEC Research Report No 8.)

13 Hartnoll R, Mitcheson M, Lewis R, Bryer S. Estimating the prevalence of opioid dcependence. Lancet 1985; i:203-5.

14 Buning EC, Coutinho RA, van Brussel GHA, van Santen GW, van Zadelhof AW. Preventing AIDS in drug addicts in Amsterdam. Lancet 1986;ii: 1435.

\section{Treating postural hypotension}

When a person stands his cardiovascular system must maintain perfusion of the brain and support a column of blood equivalent to $150 \mathrm{~mm} \mathrm{Hg}$. The response depends critically on the integrity of the autonomic nervous system and adequate plasma volume. Falls of blood pressure greater than $10 \mathrm{~mm} \mathrm{Hg}$ are common on standing in the very elderly $^{12}$; in younger patients such falls are often caused by drugs (such as antihypertensive and psychotropic drugs, diuretics, levodopa, and alcohol) or diseases associated with depleted plasma volume (such as renal disease and Addison's disease). A few patients have chronic symptomatic orthostatic hypotension because of autonomic failure. ${ }^{3}$ Some patients have Parkinson's disease-either alone or associated with widespread brain stem and basal ganglia dysfunction leading to dysarthria, ataxia, and spasticity (multisystem atrophy or Shy-Drager syndrome). Others, who may present with a disturbance of the bowel, bladder, or sexual function, have progressive isolated failure of peripheral sympathetic nerve function; this may be primary or secondary to widespread peripheral neuropathy-as in diabetes mellitus or amyloidosis.

Cardiovascular sympathetic failure is best shown by recording intra-arterial blood pressure while a patient performs Valsalva's manoeuvre. ${ }^{4}$ In those with normal function blood pressure falls a little during blowing, but this is limited by tachycardia and peripheral vasoconstriction. Once the patient finishes blowing blood pressure rises above the original value, and then there is a reflex bradycardia. In contrast, patients with autonomic failure show a progressive fall in blood pressure during blowing with a slow return to the baseline and no overshoot or bradycardia after blowing. Impaired pressor responses to stress-for example, mental arithmetic, isometric exercise, or the cold pressor testmay be shown more simply with a sphygmomanometer. Impairment of parasympathetic control may be assessed by recording beat to beat heart rate responses to deep breathing and standing. ${ }^{5}$ The normal diurnal pattern of blood pressure -a fall of $10-20 \%$ at night during sleep ${ }^{6}$ is reversed in patients with autonomic failure-they often show a pronounced rise in supine blood pressure, ${ }^{7}$ which may lead the unwary to prescribe antihypertensive drugs.

Fluid and electrolyte homoeostasis is disturbed in patients with autonomic failure. They cannot concentrate urine during overnight recumbent dehydration or produce dilute urine during upright rehydration. ${ }^{8}$ This leads to a reversed diurnal pattern of urine excretion with nocturnal diuresis and natriuresis, extracellular fluid depletion, and a profound 